\title{
Surface Electromyography: Its Role and Potential in the Development of Exoskeleton (Review)
}

\author{
DOI: $10.17691 / \mathrm{stm} 2016.8 .2 .15$
}

Received September 21, 2015

N.N. Rukina, MD, PhD, Senior Researcher, Department of Functional Diagnosis;

A.N. Kuznetsov, Junior Researcher, Department of Functional Diagnosis;

V.V. Borzikov, Junior Researcher, Department of Functional Diagnosis;

O.V. Komkova, Physician, Department of Functional Diagnosis;

A.N. Belova, MD, DSc, Professor, Head of the Department of Functional Diagnosis

Privolzhsky Federal Research Medical Center, Ministry of Health of the Russian Federation, 18 Verkhne-Volzhskaya naberezhnaya, Nizhny Novgorod, 603155, Russian Federation

This study evaluates the effectiveness of superficial electromyography (sEMG) in the development of biocontrolled exoskeletons, through an analysis based on the findings of foreign and domestic literature on the subject. A brief historical background is provided. The features reviewed include the registration, processing and analysis of the signals from superficial electromyograms in respect of biocontrol. It is demonstrated that testing exoskeleton devices in association with sEMG provides an informative analytical tool for assisting in the optimization of exoskeleton design in order to reduce the metabolic "cost" of locomotion. The use of signals from superficial myograms during the operation of an exoskeleton have also been reviewed. The role of myography in studies of the fundamental physical processes involved while adapting to an exoskeleton is described. We conclude that the potential for the use of sEMG in respect of biocontrol is related to the new technical and mathematical possibilities available for the registration, transformation and classification of bioelectrical signals from the muscles, and the isolation of their patterns of muscular activity.

Key words: superficial electromyography; exoskeleton; exoskeleton biocontrol.

\section{Historical background}

The term "exoskeleton" refers to any electromechanical system that can be worn by a person to replicate the anatomical configuration of the corresponding parts of the body, in order to enhance the power of muscles by a direct transfer of mechanical energy from the device to the human [1-3]. The history of creation of external auxiliary equipment dates back to the $19^{\text {th }}$ century, when a Russian inventor Yagn developed the "elastiped" - a device for making walking, running and jumping easier [4]. However active development of robotic devices, and in particular, exoskeletons became possible only at the end of the $20^{\text {th }}$ century when computer microprocessors, sensors and new materials appeared [5-9]. The beginning of the $21^{\text {st }}$ century has been marked not only by unprecedentedly fast development of completely new biocontrolled exoskeleton designs, but also by the transfer of exoskeletons from the sphere of science to the field of their practical application, including in rehabilitation medicine [10].

The main problems of using exoskeletons in medicine are still their weight and cost, but for so-called active exoskeleton devices it is also their dependence on an external power supply [11-13]. Because of these issues, the main tasks today are to reduce the metabolic costs to the person using the exoskeleton and to minimise the amount of energy that is required to power the exoskeleton [14-16]. The development of biomimetic device operation strategies based on reproducing and imitating the principles of biological processes plays a key role in such solutions [14]. Therefore further enhancement of exoskeletons is impossible without, not only fundamentally new control technologies and modern materials, but also without accurate data on the physiology of movement, mainly the bioelectrical activity of human muscles [14]. The method of superficial electromyography (sEMG) is designed for recording such activity, and has become an integral part of the development of modern exoskeletons allowing the investigation of muscular activity when an exoskeleton is used, in order to optimise its design. The technique also assists in exploring the use of muscle signals to operate the exoskeleton; and in gaining new fundamental knowledge of neuromuscular reorganisation for developing strategies of adaptation and compensation for damage to the body's locomotor systems [17]. The first attempts to use sEMG signals to operate an external device appeared in the 1950s-1960s and concerned a

For contacts: Nataliya N. Rukina, e-mail: rukinann@mail.ru 
hand prosthesis with one degree of freedom [18-20]. The development of modern controlled robotic devices with different degrees of freedom has, to a great extent, contributed to the importance of solving the problem of obtaining and then adequately decoding sEMG signals [21], but the approaches to the myocontrol of exoskeletons, powered prostheses and ortheses all have much in common [14].

\section{Registration, processing and analysis of superficial electromyogram signals for biocontrol}

Superficial (global, interference, total, cutaneous) electromyography is a non-invasive method of investigation allowing evaluation of the total bioelectrical activity of muscles, at rest and when performing activities with different degrees of coordination complexity. It involves detecting bioelectric activity with surface electrodes mounted on the skin over the motor points of muscles, followed by further analysis of the signal on the electromyographs [22-24]. By recording the total activity of all activated motor units sEMG can indicate the interaction of the motor units of a single muscle, or of different muscles (synergists and antagonists), and provide the possibility to investigate several muscles at the same time (their number depending on the number of electromyograph channels available) [25].

Despite the fact $s E M G$ is considered the most informative and appropriate method for the evaluation of muscle functioning during exoskeleton use, its application sets a number of challenges [26]. Firstly, the nature of the SEMG signal depends not only on the bioelectrical activity of the muscle concerned, but also on many other factors (location of the electrodes, the size of the muscle, skin contamination, external 'noise' etc.). Secondly, surface electrodes are unable to record the activity of all the muscles "responsible" for a particular movement, but only of those that are located close to the surface. Thirdly, for biocontrol it is necessary to isolate the activity of each individual muscle from the total signal. That is why special attention has to be paid to the properties, construction and placing of the electrodes, as well as to the mathematical processing of the electromyographic signals in order to exclude artefacts and to separate the signals from specific muscles [27].

The construction of the electrodes (their area, type of surface and material), their fixing and location on the muscle, orientation in respect to the fibre direction, the interelectrode distance, and the quality of skin preparation for sEMG recording are all aspects regulated by recommendations developed by a working group in the SENIAM project (surface EMG for the non-invasive assessment of muscles project). These recommendations were developed between 1996 and 1999 on the basis of an analysis of 144 studies concerning the effect of the placement and characteristics of the electrodes on the values of the recorded biopotentials of muscles, and they are now fundamental to all research in this area, making it possible to compare the results obtained in different laboratories [28-30].

To record sEMG signals, rectangular (square) and round (oval) electrodes (sensors) can be used, but ring-shaped electrodes $10 \mathrm{~mm}$ in diameter with an interelectrode distance of $20 \mathrm{~mm}$ are considered optimal. The material of the electrodes must provide good contact with the skin, low "electrode-skin" impedance and "stable" behavior over time (i.e. stability of resistance and minimal chemical reaction with the skin surface). $\mathrm{Ag}$ and $\mathrm{AgCl}$ are optimal as they provide stable conductivity with a relatively low level of noise and are readily available commercially. The electrodes are placed in areas specified for such sensors (on a line connecting two anatomical landmarks specific for each muscle) and orientated parallel with the muscle fibres. In respect of the longitudinal position, the sensor is located at the mid-point between the most distal motor point of the muscle and the distal tendon; transversely, it is located at the maximum distance from the boundary between the muscles under investigation and other muscles or structures. The number of electrodes is determined by the muscles from which the sEMG data is to be recorded. The reference electrodes are located on the wrist, on the spinous process of the $\mathrm{C} 7$ vertebra or on the ankle, depending on the muscles being studied.

When electrodes are fixed to the skin, the constructions with the set distance between the electrodes made of light materials are used. The cables are fixed with double-sided tape or an elastic bandage in such a way as to avoid signal errors during movement. To exclude artefacts and a high level of noise the patient's skin must be prepared for contact with the electrode (by cleaning with alcohol). The electrodes are positioned after the alcohol has completely dried.

Modern myographs (like the Delsys Trigno Wireless System; Delsys, USA) allow the recording of SEMG signals remotely, without using any connection cables and this considerably reduces the number of artefacts when the electromyogram is recorded, allowing it to be used when complex actions are being performed. The sEMG sensors in these myographic systems contain 3D-accelerometers and the registration of the sEMG signals can be performed simultaneously in different channels (i.e. from different muscles at the same time), which allows for the possibility of complex studies of the character of the movements [31].

SENIAM recommendations regulate the requirements for processing and modelling of the SEMG signals, in particular, the passband of the myograph and the frequency of digitising the electrical signals from the muscles $[29,30]$. The main problem with using sEMG signals for biocontrol is their changeability and instability, mainly due to external interference, electrode 
displacement, skin sweating and muscle fatigue [32, 33]. Attempts to eliminate the influence of muscle fatigue involve the use of switching devices for when the signal level varies [34] or the use of statistical methods, for example, filtration [35]. Elimination of electrophysical and mechanically-caused artefacts can be achieved with the use of special filters in the electromyograph and by appropriate selection of the frequency for digitising the electrical signal from the muscles [36]. One of the main problems with sEMG recording is crosstalk, i.e. interference caused by the "leaking" of signals from adjacent muscles. Mesin at al. and Farina et al. [37-42] give a detailed analysis of methods for identification of crosstalk by simulating the crosstalk during electromyography; to isolate the signal from the target muscle one can use different pattern-recognition algorithms for sEMG signal decoding, based on the strategy of "pattern recognition". Increased effectiveness of signal isolation, to just that corresponding to the muscular effort under study, is achieved by synchronisation of the sEMG with video analysis of the corresponding movements [43].

When recording sEMGs of the muscles of the pelvic girdle and the lower limbs, the following muscles are studied and used for biocontrol: gluteus maximus (gluteusmedius), tensor fasciae latae, quadriceps femoris (rectusfemoris), quadriceps femoris (vastusmedialis), quadriceps femoris (vastuslateralis), biceps femoris (long and short heads), and the semitendinosus. Recording sEMGs of the muscles of the lower leg and foot includes the following muscles: the tibialisanterior, peroneuslongus, peroneus brevis, soleus, and the gastrocnemius. For sEMGs of the muscles of the shoulder, neck and upper limb, the following muscles are used for biocontrol: the deltoideus anterior, deltoideus medius, biceps brachii, triceps brachii, flexor carpira dialis, extensor carpiulnaris, and the pectoralis major $[26,31,43,44]$. As a rule, the recording is performed for several muscles at the same time (the number of muscles is determined by the number of myograph channels available), and synchronously from the right and the left sides of the body.

For each muscle, over a set period of time (for example, for a given movement phase) the following range of sEMG parameters are analysed: the averaged maximum and minimum values of the bioelectrical signal for the particular movement cycle; the total activity of the muscle (integral activity); the percentage correlation of the periods of tension and relaxation; the frequency characteristics of the muscle [31, 43, 44]. For groups of muscles, the parameters of synchronicity of the work of agonist and antagonist muscles are calculated, and the muscle synergy is analysed.

The most difficult task in using biosignals for exoskeleton control is the identification of the typical sEMG patterns of different movements, or of recognisable and stable patterns of bioelectrical muscle activity associated with the activation of each set of muscles during particular movements [45]. To solve this task the strategy of pattern recognition is used: the recorded SEMG patterns are used for "training" a computer program and to develop an algorithm to predict the body movements matching the recorded pattern [46]. The two main "steps" of algorithmisation for the pattern recognition of movements are: extraction of information from all the signals obtained from the electrodes, followed by their classification into different patterns (images) [47]. The methods of information extraction about the representative features of the sEMG recordings are based on calculation of their coefficients of variation and autoregression, and on an analysis of their time-frequency and time-space characteristics [48]. Classification of signals can be performed with a variety of methods including linear discriminate analysis, Bayesian statistics, vector analysis, and the artificial neural network method [41, 49-55].

It has been established that SEMGs of the body and limb muscles during walking can be represented as a linear combination of four or five patterns of muscle activation, reflecting the processes of muscular synergies [56-58]. For some categories (for example, in children) there are normative data about the sEMG patterns for healthy people [44] and these are suitable for comparative analysis with the data obtained when evaluating robotic devices [43].

\section{The importance of superficial electromyography in the evaluation of energy consumption and the optimisation of exoskeleton design}

Human movements are normally regulated to minimise energy consumption [59-61]. As muscles need energy for contraction, the kinematics of movement and the metabolic costs are closely linked [62-68]. It requires a certain amount of energy when a muscle is under tension and increases in length (the so-called negative phase of contraction); in the case of isometric muscle contraction, the energy consumption is somewhat greater, while in the case of active muscle contraction, i.e. shortening (the positive phase) the consumption of energy by the muscle is at a maximum [69-71]. All the metabolic costs increase the greater the degree of muscle contraction. In general, the overall energy consumption of a muscle is determined by the relative amounts of negative, positive and isometric work involving that muscle during that one specific movement [72]. A reduction of energy consumption can be achieved by reducing the period of active muscle contraction. Moreover, experiments have shown that tendons capable of storing and releasing "elastic" energy play a key role in reducing muscle energy consumption and in saving energy [73-78].

When an exoskeleton is used its movements must 
be adjusted to match the physiological ones, so it is important to evaluate the connection between the kinematics of movements and the metabolic costs to the person using the robotic device. The design of an exoskeleton frequently offers active assistance in limb movements by using special drives and rods to reduce the mechanical load on muscles and to save on their energy consumption; the metabolic costs of a muscle can typically be reduced four-fold [14]. By contrast, ignoring physiological laws (for instance, by interfering with the natural pattern of a stepping movement) can make use of the robotic device excessively energyconsuming for the person [14]. Wearing an exoskeleton can cause changes in the afferent sensory signals from muscles and joints, the sensor-motor connections and, as a result, in the physiological muscle patterns [31]. In this context, Gordon et al. showed that when a person wears an exoskeleton the activity of the soleus muscle is changed, even if the person is healthy [79].

Determination of the amplitude and total electromyographic activity of operating muscles, reflecting the degree and duration of their contraction, can reveal the constant activity of one muscle or damaged synergism of muscle operation, allowing indirect evaluation of the likely energy consumption of using the exoskeleton [80]. Identification of those "target" muscles operating in overload mode can improve the design of the device and more effectively minimise the metabolic costs to the body during any particular movement [14].

Electromyographic research provides the opportunity to evaluate the effect of new exoskeleton devices. So, by electromyographic examination, Ferris et al. showed, that improvements in the structure of a lower limb exoskeleton could be made by adding passive elastic rods to the regions of the knee joints, thereby reducing the recruitment of the muscle fibres of the key leg muscles, but without any changes to the dynamics of walking, yet significantly reducing the metabolic "cost" of walking and running [81].

Schuler et al. studied the patterns and activity of sEMGs in 8 children with neuroorthopedic pathology, in the processing of training in walking skills with an exoskeleton. The data obtained were compared with the results of sEMG-examination of these children during walking on a treadmill without the support, and with the results of surveys of healthy children. The SEMG registration was performed on the tibialis anterior, gastrocnemius lateralis, vastus medialis and biceps femoris muscles. The SEMG signal amplitudes of the muscles were analysed during the phases of support and leg transfer. The authors showed that the use of an exoskeleton for the sick children induced an noticeable increase in muscular activity, and activation of the physiological muscular patterns. If sEMG results from the leg muscles during normal walking on the treadmill testified to a the switching on of compensatory mechanisms, the use of the electromyographic patterns with the exoskeleton could reflect the real recovery of motor functions [43].

To evaluate a new rehabilitation exoskeleton device Venemanc et al. studied the bioelectric activity of eight key muscles during walking. The study, performed on a single patient, showed that the electromyographic values during walking with the device corresponded to the normal values of a healthy individual during free walking; this demonstrated the physiological value of the robotic device [82].

Sylos-Labini et al. [31] made a detailed analysis of the changes in sEMG patterns while six healthy individuals and four patients with spine and spinal cord injuries were wearing exoskeletons. Contrary to expectations, the electromyographic activity of the leg muscles of healthy people during walking in the exoskeleton was analogous, or even exceeded that during free-walking. At the same time the patients with spinal cord injury exhibited low bioelectrical activity in the leg muscles and showed high variability, in particular in the hamstring muscles. Generally the results demonstrated nonlinear reorganisation of the patterns of muscular activity when a robotic device was being used. In the authors' opinion, these findings may help in understanding the adaptation processes of locomotor activity patterns when an external exoskeleton is used in healthy people, and in those with neuromuscular pathology. The authors drew the conclusion that the results of their work with pathological conditions showed the presence of various neuromotor strategies aimed at compensating for the reduced muscular function [31, 57, 83].

In general, SEMG registration and analysis of exoskeleton devices during testing allows the identification and minimisation of muscular activity associated with the most costly metabolic components of locomotion (for example, leg pushing or leg transfer during walking, and the muscle contractions used to provide rigidity in the joints), as well as the diagnosis of non-adaptive compensatory strategies. In this case sEMG is an informative analytical tool, helping to optimise exoskeleton design to reduce the metabolic "cost" of locomotion [81].

\section{The use of superficial electromyogram signals for exoskeleton control}

Initially, power sensors were built into exoskeletons to control them [84]. However, a number of problems were associated with the use of such sensors (signal delay, difficulties in distinguishing between the signals from the subject and external signals) [26]. At the beginning of the 1990s, to eliminate these problems, the use sEMG signals was suggested because an electromyographic signal from the striated muscles of a healthy human depends only on the intentions of the person themselves and directly reflects the level of muscular activity in 
real-time, allowing the possibility to predict the desired movement-intention before the muscle actually starts to contract (thus the biocontrol signal delay is eliminated) $[85,86]$. In recent years, with the development of modern technology, this method has been widely used for exoskeleton biocontrol [79, 87-91]. A computer records the first signs of electromyographic activity before the actual movement begins and transfers these signals to the device drives; as a result, the exoskeleton drives operate synchronously with the muscles that must take part in the planned movement, intensifying their action [10].

The main "steps" in the use of sEMG signals for biocontrol are: the identification of the signals from particular muscles; determination of the extent of the 'contribution' of the bioelectrical activity in these muscles beyond that which can be recorded with SEMG, and the selection of a model for movement control [26].

A considerable element of the control by SEMG is based on "on-off" principles, i.e. the model involves switching the movement on at a constant rate in one direction or the cessation of such movement [92]. The on-off model is used in passive exoskeletons and does not allow for the recognition of more complex intentions of the user in real-time [93]. For this reason other models are being developed, namely using proportional myoelectric control that presupposes constant analysis of the sEMG signals in the real-time to allows more effective control of active exoskeletons of the upper limbs for example [93-99]. The intended end-point of limb movement is determined by the information from feedback sensors (angle, power). For example, the feedback can be based on information from goniometric (angle-measuring) sensors, and the sEMG signal is used for the calculation of the offset correction in the joint [100]. This approach is exemplified in a study by Tang et al. [93] who developed an experimental protocol for recording SEMG signals and the angles of elbow flexion with a further procedure for information extraction and the building a model of proportional myoelectrical control. The value of the angle of elbow flexion expected according to recognition of the myoelectric patterns was then transformed into signals sent to the joint drives (pneumatic muscles). Experiments proving the effectiveness of this scheme of controlling an active exoskeleton of the upper limb were performed [93].

Another approach involves direct power-control of the external device: sEMG signals are converted into values representing the force the body is applying to the limb and are compared with the forces recorded by a power sensor fixed onto the limb. The difference between these forces is communicated to the control unit operating the drives [99]. This method of direct conversion of the recorded SEMG-signals into muscle strength was proposed for controlling a hand exoskeleton with 16 joints (4 for each of 4 fingers) [26].

The success of models of proportional myoelectrical control to a great extent depends on the reliability of decoding the muscular biopotential for a planned movement. The most promising method of classification of signals for this type of model is that of artificial neuron chains, due to the short time required for training of the classifier [98]. So, Su et al. demonstrated an active exoskeleton for the upper limbs where the sEMG signals are classified after the training of an artificial neuron network; the classifier for the sEMG-patterns recognises movements in the hand joints with a high degree of reliability and can accurately predict the planned movements in order to put the mechanism of the exoskeleton into action [89].

The technologies of exoskeleton myocontrol are constantly being improved. For instance, a method of sEMG control has been proposed based on impedance change, as this allows not only the features of the electromyographic signal to be taken into account, but also the properties of the human body [87]. The authors proved that this method is simple enough to adjust for any user and helps effectively to operate the robotic device when the user makes targeted movements.

\section{The role of myography in studying fundamental physiological processes during adjustment to an exoskeleton}

To create new exoskeletons, fundamental knowledge of the physiology of movements in normal and in pathological conditions is required. The physiological characteristics of human movements made with an exoskeleton can be an important source of new information about the metabolic "cost" of human locomotion in these different conditions [14]. Use of an exoskeleton and forced control of the limbs can change the profiles of muscular activation, change the patterns of muscular activity, the kinematics of walking and other movements, and change the "locomotor scheme of the body" even for a healthy human [101, 102]. It is known that the locomotor system of a human can flexibly adjust to changing requirements of the neuromuscular system [103-105], yet the effect of robotic devices on locomotor functions and on their recovery in the case of pathology has not been sufficiently studied [31]. It is necessary to find answers to the following questions: 1 ) how long does it take to train a human to use an active exoskeleton; 2) what compensatory and adaptive neuronal mechanisms are switched on; 3) how flexible and stable are the movements performed with an exoskeleton; 4) how do metabolic costs change for a human using an exoskeleton; 5) what is the relative input of each limb joint into the metabolic "cost" of a given movement; 6 ) do the properties and strength of muscles limit the flexibility and mobility of movements in an exoskeleton [14, 106].

Using sEMG can help to answer to some of these questions, for example, it allows study of the modulation of muscular activity patterns when an exoskeleton is 
used, providing a key to understanding compensatory strategies and the plasticity of neuronal chains in the body [106].

This is exemplified in the work of Ferris et al. [103] who carried out an experiment on healthy volunteers, studying the potential of the shin muscles for functional reassignment using SEMG. The signal from the soleus muscle was transferred to the drive of the exoskeleton that activated dorsiflexion of the foot, i.e. creating artificial obstacles during walking. In these conditions the maintenance of the normal profiles for this muscle would be metabolically costly and mechanically ineffective. With repetition of attempts there was a considerable reduction in the myoelectrical activity of the soleus muscle which allowed the subject to minimise the negative impact of the exoskeleton. The authors came to the conclusion that the system of human control of locomotion can regulate both the profiles of activation of single muscles, and of the motor patterns in general, in order to reduce metabolic costs [107].

\section{Conclusion}

Information obtained from superficial electromyography is being used in the development of biocontrolled exoskeletons and in the assessment of their effectiveness, it also impacts on our understanding of the physiological processes of adaptation and compensation in the pathology of the locomotion system when robotic devices are used. The potential for the development of this method in respect of biocontrol is linked to new technical and mathematical possibilities for the registration, transformation and classification of the bioelectrical signals of muscles and the patterns of muscle activity.

Study Funding. The work was supported by the Ministry of Education and Science of the Russian Federation under the Federal Grant Program "Studies and Developments in Priority Directions of the ScientificTechnical Complex of Russia for 2014-2020". Grant agreements No.14.578.21.0094 dated 24.11.2014 (the unique identifying number of the project is RFMEFI57814X0094).

Conflicts of Interest. The authors declare no conflicts of interest.

\section{References}

1. Huang V.S., Krakauer J.W. Robotic neurorehabilitation: a computational motor learning perspective. J Neuroeng Rehabil 2009; 6: 5, http://dx.doi.org/10.1186/1743-0003-6-5.

2. Rocon E., Belda-Lois J.M., Ruiz A.F., Manto M., Moreno J.C., Pons J.L. Design and validation of a rehabilitation robotic exoskeleton for tremor assessment and suppression. IEEE Trans Neural Syst Rehabil Eng 2007; 15(3): 367-378, http://dx.doi.org/10.1109/TNSRE.2007.903917.

3. Mankala K.K., Banala S.K., Agrawal S.K. Novel swingassist un-motorized exoskeletons for gait training. J Neuroeng Rehabil 2009; 3(6): 24, http://dx.doi.org/10.1186/1743-0003-6-24.

4. Exoskeleton ili kto izobrel ekzoskelet [Exoskeleton, or who invented the exoskeleton]. URL: http://top100invent. blogspot.com/2010/12/exoskeleton.html.

5. Hughes J. Powered lower limb orthotics in paraplegia. Paraplegia 1972; 9(4): 191-193, http://dx.doi.org/10.1038/ sc.1971.31.

6. Vukobratovic M., Hristic D., Stojiljkovic Z. Development of active anthropomorphic exoskeletons. Med Biol Eng 1974; 12(1): 66-80, http://dx.doi.org/10.1007/BF02629836.

7. Vukobratović M., Borovac B., Surla D., Stokić D. Biped locomotion: dynamics, stability, control and application. Scientific Fundamentals of Robotics 7. Springer Berlin Heidelberg; 1990; http://dx.doi.org/10.1007/978-3-642-83006-8.

8. Seireg A., Grundman J.G. Design of a multitask exoskeletal walking device for paraplegics. In: Biomechanics of medical devices. New York: Marcel Dekker, Inc.; 1981; p. 569-639.

9. Townsend M.A., Lepofsky R.J. Powered walking machine prosthesis for paraplegics. Med Biol Eng 1976; 14(4): 436-444, http://dx.doi.org/10.1007/BF02476121.

10. Vorobyev A.A., Petrukhin A.V., Zasypkina O.A., Krivonozhkina P.S., Pozdnyakov A.M. Exoskeleton as a new means in habilitation and rehabilitation of invalids (review). Sovremennye tehnologii v medicine 2015; 7(2): 185-197, http://dx.doi.org/10.17691/stm2015.7.2.22.

11. Kawamoto H., Sankai Y. Power assist method based on phase sequence and muscle force condition for HAL. Adv Robotic 2005; 19(7): 717-734, http://dx.doi. org/10.1163/1568553054455103.

12. Zoss A., Kazerooni H. Design of an electrically actuated lower extremity exoskeleton. Adv Robotic 2006; 20(9): 967988, http://dx.doi.org/10.1163/156855306778394030.

13. Amundson K., Raade J., Harding N., Kazerooni $H$. Development of hybrid hydraulic-electric power units for field and service robots. Adv Robotic 2006; 20(9): 1015-1034, http://dx.doi.org/10.1163/156855306778394058.

14. Ferris D.P., Sawicki G.S. Daley M.A. A physiologist's perspective on robotic exoskeletons for human locomotion. Int J HR 2007; 4(3): 507-528, http://dx.doi.org/10.1142/ s0219843607001138.

15. Brooks R.A. The robots are here. Technol Rev 2004; 107: 30 .

16. Low K.H., Liu X., Goh C.H., Yu H. Locomotive control of a wearable lower exoskeleton for walking enhancement. J Vibrat Control 2006; 12(12): 1311-1336, http://dx.doi. org/10.1177/1077546306070616.

17. Gordon K.E., Wu M., Kahn J.H., Schmit B.D. Feedback and feedforward locomotor adaptations to ankle-foot load in people with incomplete spinal cord injury. J Neurophysiol 2010; 104(3): 1325-1338, http://dx.doi.org/10.1152/jn.00604.2009.

18. Battye C.K., Nightengale A., Whillis J. The use of myoelectric current in the operation of prostheses. $J$ Bone Joint Surg $\mathrm{Br}$ 1955; 37-B(3): 506-510.

19. Bottomley A.H. Myoelectric control of powered prostheses. J Bone Joint Surg Br 1965; 47: 411-415.

20. Finley F.R., Wirta R.W. Myocoder studies of multiple myopotential response. Arch Phys Med Rehabil 1967; 48(11): 598-601.

21. Peerdeman B., Boere D., Witteveen $H_{\text {., }}$ Huis in 'tVeld R., Hermens H., Stramigioli S., Rietman H., Veltink P., Misra S. Myoelectric forearm prostheses: state of the art from a user-centered perspective. J Rehabil Res Dev 2011; 48(6): 719, http://dx.doi.org/10.1682/jrrd.2010.08.0161.

22. Gekht B.M. Teoreticheskaya i klinicheskaya 
elektromiografiya [Theoretical and clinical electromyography]. Leningrad: Nauka; 1990.

23. Badalyan L.O., Skvortsov I.A. Klinicheskaya elektromiografiya [Clinical electromyography]. Moscow: Meditsina; 1986.

24. Aminoff M. Electromyography in clinical practice. Addison-Wesley; 1978.

25. Wakeling J.M. Spectral properties of the surface EMG can characterize motor unit recruitment strategies. J Appl Physiol 2008; 105(5): 1676-1677.

26. Fleischer C., Wege A., Kondak K., Hommel G. Application of EMG signals for controlling exoskeleton robots. Biomed Tech 2006; 51(5-6): 314-319, http://dx.doi. org/10.1515/BMT.2006.063.

27. Farina D., Mesin L., Marina S., Merletti R.A. Surface EMG generation model with multilayer cylindrical description of the volume conductor. IEEE Trans Biomed Eng 2004; 51(3): 415-426, http://dx.doi.org/10.1109/TBME.2003.820998.

28. Hermens H.J., Freriks B., Disselhorst-Klug C., Rau G. Development of recommendations for SEMG sensors and sensor placement procedures. J Electromyogr Kinesiol 2000; 10(5): 361-374, http://dx.doi.org/10.1016/S1050-6411(00) 00027-4.

29. SENIAM. Book 8. European recommendations for surface electromyography. URL: http://www.seniam.org.

30. SENIAM. Recommendations for sensor locations in hip or upper leg muscles. URL: http://www.seniam.org/ quadricepsfemorisvastusmedialis.html.

31. Sylos-Labini F., La Scaleia V., d'Avella A., Pisotta I., Tamburella F., Scivoletto G., Molinari M., Wang S., Wang L., van Asseldonk E., van der Kooij H., Hoellinger T., Cheron G., Thorsteinsson F., Ilzkovitz M., Gancet J., Hauffe R., Zanov F., Lacquaniti F., Ivanenko Y.P. EMG patterns during assisted walking in the exoskeleton. Front Hum Neurosci 2014; 8: 423, http://dx.doi.org/10.3389/fnhum.2014.00423.

32. Merletti R., Aventaggiato M., Botter A., Holobar A., Marateb $H$., Vieira T. Advances in surface EMG: recent progress in detection and processing techniques. Crit Rev Biomed Eng 2011; 38(4): 305-345, http://dx.doi.org/10.1615/ CritRevBiomedEng.v38.i4.10.

33. Chowdhury R.H., Reaz M.B., Ali M.A., Bakar A.A., Chellappan K., Chang T.G. Surface electromyography signal processing and classification techniques. Sensors (Basel) 2013; 13(9): 12431-12466, http://dx.doi.org/10.3390/ s130912431.

34. Artemiadis P.K., Kyriakopoulos K.J. A switching regime model for the EMG-based control of a robot arm. IEEE Trans Syst Man Cybern B Cybern 2011; 41(1): 53-63, http://dx.doi. org/10.1109/TSMCB.2010.2045120.

35. Dimitrova N.A., Dimitrov G.V. Interpretation of EMG changes with fatigue: facts, pitfalls, and fallacies. J Electromyogr Kinesiol 2003; 13(1): 13-36, http://dx.doi. org/10.1016/S1050-6411(02)00083-4.

36. Dhiman R., Hooda S.D. Detecting the useful electromyogram signals-extracting, conditioning and classification. Indian Journal of Computer Science and Engineering 2011; 2(4): 634-637.

37. Mesin L., Farina D. A model for surface EMG generation in volume conductors with spherical inhomogeneities. IEEE Trans Biomed Eng 2005; 52(12): 1984-1893, http://dx.doi. org/10.1109/TBME.2005.857670.

38. Mesin L. Simulation of surface EMG signals for a multilayer volume conductor with a superficial bone or blood vessel. IEEE Trans Biomed Eng 2008; 55(6): 1647-1657, http://dx.doi.org/10.1109/tbme.2008.919104.

39. Farina D., Cescon C. Concentric-ring electrode system for noninvasive detection of single motor unit activity. IEEE Trans Biomed Eng 2001; 48(11): 1326-1334, http://dx.doi. org/10.1109/10.959328.

40. Farina D., Cescon C., Merletti R. Influence of anatomical, physical and detection-system parameters on surface EMG. Biol Cybern 2002; 86(6): 445-456, http://dx.doi. org/10.1007/s00422-002-0309-2.

41. Farina D., Févotte C., Doncarli C., Merletti R. Blind separation of linear instantaneous mixtures of nonstationary surface myoelectric signals. IEEE Trans Biomed Eng 2004; 1555-1567, http://dx.doi.org/10.1109/TBME.2004.828048.

42. Farina D., Lucas M.F., Doncarli C. Optimized wavelets for blind separation of nonstationary surface myoelectric signals. IEEE Trans Biomed Eng 2008; 55(1): 78-86, http:// dx.doi.org/10.1109/TBME.2007.897844.

43. Schuler T.A., Müller R., van Hedel H.J. Leg surface electromyography patterns in children with neuro-orthopedic disorders walking on a treadmill unassisted and assisted by a robot with and without encouragement. $J$ Neuroeng Rehabil 2013; 10: 78, http://dx.doi.org/10.1186/1743-0003-10-78.

44. Chang W.N., Lipton J.S., Tsirikos A.I., Miller F. Kinesiological surface electromyography in normal children: range of normal activity and pattern analysis. J Electromyogr Kinesiol 2007; 17(4): 437-445, http://dx.doi.org/10.1016/j. jelekin.2006.02.003.

45. Lorrain T., Jiang N., Farina D. Influence of the training set on the accuracy of surface EMG classification in dynamic contractions for the control of multifunction prostheses. Neuroeng Rehabil 2011; 8: 25, http://dx.doi.org/10.1186/17430003-8-25.

46. Scott R.N., Parker P.A. Myoelectric prostheses: state of the art. J Med Eng Technol 1988; 12(4): 143-151, http://dx.doi. org/10.3109/03091908809030173.

47. Hudgins B., Parker P., Scott R.N. A new strategy for multifunction myoelectric control. IEEE Trans Biomed Eng 1993; 40(1): 82-94, http://dx.doi.org/10.1109/10.204774.

48. Englehart K., Hudgins B. A robust, real-time control scheme for multifunction myoelectric control. IEEE Trans Biomed Eng 2003; 50(7): 848-854, http://dx.doi.org/10.1109/ TBME.2003.813539.

49. Maclsaac D.T., Parker P.A., Englehart K.B., Rogers D.R. Fatigue estimation with a multivariable myoelectric mapping function. IEEE Trans Biomed Eng 2006; 53(4): 694-700, http:// dx.doi.org/10.1109/TBME.2006.870220.

50. Huang Y., Englehart K.B., Hudgins B., Chan A.A Gaussian mixture model based classification scheme for myoelectric control of powered upper limb prostheses. IEEE Trans Biomed Eng 2005; 52(11): 1801-1811, http://dx.doi. org/10.1109/TBME.2005.856295.

51. Farina D., Merletti R., Indino B., Graven-Nielsen T. Surface EMG crosstalk evaluated from experimental recordings and simulated signals. Reflections on crosstalk interpretation, quantification and reduction. Methods Inf Med 2004; 43(1): 30-35.

52. Kiguchi K., Imada Y., Liyanage M. EMG-based neurofuzzy control of a 4DOF upper-limb power-assist exoskeleton. Conf Proc IEEE Eng Med Biol Soc 2007; 2007: 3040-3043, http://dx.doi.org/10.1109/IEMBS.2007.4352969.

53. Chu J.U., Moon I., Mun M.S. A real-time EMG pattern recognition system based on linear-nonlinear feature projection 
for a multifunction myoelectric hand. IEEE Trans Biomed Eng 2006; 53(11): 2232-2239, http://dx.doi.org/10.1109/ tbme.2006.883695.

54. Shenoy P., Miller K.J., Crawford B., Rao R. Online electromyographic control of a robotic prosthesis. IEEE Trans Biomed Eng 2008; 55(3): 1128-1135, http://dx.doi.org/10.1109/ TBME.2007.909536.

55. Campanini I., Merlo A., Degola P., Merletti R., Vezzosi G., Farina D. Effect of electrode location on EMG signal envelope in leg muscles during gait. J Electromyogr Kinesiol 2007; 17(4): 515-526, http://dx.doi.org/10.1016/j. jelekin.2006.06.001.

56. Clark D.J., Ting L.H., Zajac F.E., Neptune R.R., Kautz S.A. Merging of healthy motor modules predicts reduced locomotor performance and muscle coordination complexity post-stroke. J Neurophysiol 2010; 103(2): 844-857, http:// dx.doi.org/10.1152/jn.00825.2009.

57. Ivanenko Y.P., Poppele R.E., Lacquaniti F. Five basic muscle activation patterns account for muscle activity during human locomotion. J Physiol 2004; 556(Pt 1): 267-282, http:// dx.doi.org/10.1113/jphysiol.2003.057174.

58. Lacquaniti F., Ivanenko Y.P., Zago M. Patterned control of human locomotion. J Physiol 2012; 590(10): 2189-2199, http://dx.doi.org/10.1113/jphysiol.2011.215137.

59. McNeill Alexander R. Energetics and optimization of human walking and running: the 2000 Raymond Pearl memorial lecture. Am J Hum Biol 2002; 14(5): 641-648, http:// dx.doi.org/10.1002/ajhb.10067.

60. Bertram J.E., Ruina A. Multiple walking speedfrequency relations are predicted by constrained optimization. J Theor Biol 2001; 209(4): 445-453, http://dx.doi.org/10.1006/ jtbi.2001.2279.

61. Donelan J.M., Kram R., Kuo A.D. Mechanical work for step-to-step transitions is a major determinant of the metabolic cost of human walking. J Exp Biol 2002; 205(Pt 23): 3717-3727.

62. Saunders J.B., Inman V.T., Eberhart H.D. The major determinants in normal and pathological gait. $J$ Bone Joint Surg Am 1953; 35-A(3): 543-558.

63. Alexander R.M., Bennet-Clark H.C. Storage of elastic strain energy in muscle and other tissues. Nature 1977; 265(5590): 114-117, http://dx.doi.org/10.1038/265114a0.

64. Taylor C.R. Relating mechanics and energetics during exercise. Adv Vet Sci Comp Med 1994; 38A: 181-215.

65. Elftman $\mathrm{H}$. The function of muscles in locomotion. Am J Physiol 1939; 125: 357-366.

66. Williams K.R., Cavanagh P.R. Relationship between distance running mechanics, running economy, and performance. J Appl Physiol 1987; 63(3): 1236-1245.

67. Cavanagh P.R., Kram R. Mechanical and muscular factors affecting the efficiency of human movement. Med Sci Sports Exerc 1985; 17(3): 326-331, http://dx.doi. org/10.1249/00005768-198506000-00005.

68. Williams K.R. The relationship between mechanical and physiological energy estimates. Med Sci Sports Exerc 1985; 17(3): 317-325, http://dx.doi.org/10.1249/00005768198506000-00004.

69. Margaria R. Biomechanics and energetics of muscular exercise. England: Clarendon Press; 1976.

70. Bobbert A.C. Physiological comparison of three types of ergometry. J Appl Physiol 1960; 15: 1007-1014.

71. Abbott B.C., Bigland B., Ritchie J.M. The physiological cost of negative work. J Physiol 1952; 117(3): 380-390, http:// dx.doi.org/10.1113/jphysiol.1952.sp004755.
72. Cavagna G.A., Kaneko M. Mechanical work and efficiency in level walking and running. J Physiol 1977; 268(2): 647-681, http://dx.doi.org/10.1113/jphysiol.1977.sp011866.

73. Griffiths R.I. Shortening of muscle fibers during stretch of the active cat medial gastrocnemius muscle: the role of tendon compliance. J Physiol 1991; 436: 219-236.

74. Roberts T.J., Marsh R.L., Weyand P.G., Taylor C.R. Muscular force in running turkeys: the economy of minimizing work. Science 1997; 275(5303): 1113-1115, http://dx.doi. org/10.1126/science.275.5303.1113.

75. Daley M.A., Biewener A.A. Muscle force-length dynamics during level versus incline locomotion: a comparison of in vivo performance of two guinea fowl ankle extensors. $J$ Exp Biol 2003; 206(Pt 17): 2941-2958, http://dx.doi. org/10.1242/jeb.00503.

76. Fukunaga T., Kubo K., Kawakami Y., Fukashiro S., Kanehisa $H_{\text {., }}$ Maganaris C.N. In vivo behaviour of human muscle tendon during walking. Proc Biol Sci 2001; 268(1464): 229-233, http://dx.doi.org/10.1098/rspb.2000.1361.

77. Lichtwark G.A., Bougoulias K., Wilson A.M. Muscle fascicle and series elastic element length changes along the length of the human gastrocnemius during walking and running. $J$ Biomech 2007; 40: 157-164, http://dx.doi. org/10.1016/j.jbiomech.2005.10.035.

78. Ishikawa M., Komi P.V., Grey M.J., Lepola V., Bruggemann G.P. Muscle-tendon interaction and elastic energy usage in human walking. J Appl Physiol 2005; 99(2): 603-608, http://dx.doi.org/10.1152/japplphysiol.00189.2005.

79. Gordon K.E., Kinnaird C.R., Ferris D. Locomotor adaptation to a soleus EMG-controlled antagonistic exoskeleton. Neurophysiol 2013; 109(7): 1804-1814, http:// dx.doi.org/10.1152/jn.01128.2011.

80. Orendurff M.S., Segal A.D., Klute G.K., McDowell M.L., Pecoraro J.A., Czerniecki J.M. Gait efficiency using the C-Leg. J Rehabil Res Dev 2006; 43(2): 39-46, http://dx.doi. org/10.1682/JRRD.2005.06.0095.

81. Ferris D.P., Bohra Z.A., Lukos J.R., Kinnaird C.R. Neuromechanical adaptation to hopping with an elastic anklefoot orthosis. J Appl Physiol 2006; 100(1): 163-170, http:// dx.doi.org/10.1152/japplphysiol.00821.2005.

82. Veneman J.F., Kruidhof R., Hekman E.E., Ekkelenkamp R., Van Asseldonk E.H., van der Kooij H. Design and evaluation of the LOPES exoskeleton robot for interactive gait rehabilitation. IEEE Trans Neural Syst Rehabil Eng 2007; 15(3): 379-386, http://dx.doi.org/10.1109/ TNSRE.2007.903919.

83. Duysens J., De Groote F., Jonkers I. The flexion synergy, mother of all synergies and father of new models of gait. Front Comput Neurosci 2013; 7: 14, http://dx.doi. org/10.3389/fncom.2013.00014.

84. Zecca M., Micera S., Carrozza M.C., Dario P. Control of multifunctional prosthetic hands by processing the electromyographical signal. Crit Rev Biomed Eng 2002; 30(46): 459-485, http://dx.doi.org/10.1615/critrevbiomedeng.v30. i456.80.

85. Benjuya N., Kenney S.B. Myoelectric hand orthosis. J Prosthet Orthot 1990; 2(2): 149-154, http://dx.doi. org/10.1097/00008526-199001000-00011.

86. Farry K.A., Walker I.D., Baraniuk G.B. Myoelectric teleoperation of a complex robotic hand. IEEE Trans Robot Automat 1996; 12(5): 775-788, http://dx.doi. org/10.1109/70.538982.

87. Kiguchi K., Hayashi Y. An EMG-based control for an 
upper-limb power-assist exoskeleton robot. IEEE Trans Syst Man Cybern Part B Cybern 2012; 42(4): 1064-1071, http:// dx.doi.org/10.1109/TSMCB.2012.2185843.

88. Yagi E., Harada D., Kobayashi M. Upper-limb powerassist control for agriculture load lifting. Int J Autom Technol 2009; 3(6): 716-722, http://dx.doi.org/10.20965/ijat.2009.p0716.

89. Su H., Li Z., Li G., Yang C. EMG-based neural network control of an upper-limb power-assist exoskeleton robot. In: Advances in neural networks - ISNN 2013. Springer Science + Business Media; 2013; p. 204-211, http://dx.doi. org/10.1007/978-3-642-39068-5_25.

90. Khokhar Z.O., Xiao Z.G.., Menon C. Surface EMG pattern recognition for real-time control of a wrist exoskeleton. Biomed Eng Online 2010; 9: 41, http://dx.doi.org/10.1186/1475925X-9-41.

91. Gopura R.A.R.C., Kiguchi K., Li Y. SUEFUL-7: A 7DOF upper-limb exoskeleton robot with muscle-modeloriented EMG-based control. In: 2009 IEEE/RSJ International Conference on Intelligent Robots and Systems. IEEE; 2009; p. 1126-1131, http://dx.doi.org/10.1109/iros.2009.5353935.

92. Chan B., Sia C., Wong F., Chin R., Dargham J.A., Siang Y.S. Analysis of surface electromyography for on-off control. Adv Mater Res 2013; 701: 435-439, http://dx.doi. org/10.4028/www.scientific.net/AMR.701.435.

93. Tang Z., Zhang K., Sun S., Gao Z., Zhang L., Yang Z. An upper-limb power-assist exoskeleton using proportional myoelectric control. Sensors (Basel) 2014; 14(4): 6677-6694, http://dx.doi.org/10.3390/s140406677.

94. Fougner A., Stavdahl O., Kyberd P., Losier Y., Parker P. Control of upper limb prostheses: terminology and proportional myoelectric control - a review. IEEE Trans Neural Syst Rehabil Eng 2012; 20(5): 663-677, http://dx.doi.org/10.1109/ TNSRE.2012.2196711.

95. Pistohl T., Cipriani C., Jackson A., Nazarpour K. Adapting proportional myoelectric-controlled interfaces for prosthetic hands. Conf Proc IEEE Eng Med Biol Soc 2013; 2013: 61956198, http://dx.doi.org/10.1109/EMBC.2013.6610968.

96. Nielsen J.L., Holmgaard S., Jiang N., Englehart K., Farina D., Parker P. Enhanced EMG signal processing for simultaneous and proportional myoelectric control. Conf Proc IEEE Eng Med Biol Soc 2009; 2009: 4335-4338, http://dx.doi. org/10.1109/IEMBS.2009.5332745.

97. Ferris D.P., Lewis C.L. Robotic lower limb exoskeletons using proportional myoelectric control. Conf Proc IEEE
Eng Med Biol Soc 2009; 2009: 2119-2124, http://dx.doi. org/10.1109/IEMBS.2009.5333984.

98. Zimenko K.A., Borgul' A.S., Margun A.A. Analysis and processing of electromyogram signals. Nauchno-tekhnicheskiy vestnik informatsionnykh tekhnologiy, mekhaniki i optiki 2013; 1(83): 41-43.

99. Rosen J., Brand M., Fuchs M.B., Arcan M. A myosignal-based powered exoskeleton system. IEEE Trans Syst, Man, Cybern A 2001; 31(3): 210-222, http://dx.doi. org/10.1109/3468.925661.

100. Guizzo E., Goldstein H. The rise of the body bots [robotic exoskeletons]. IEEE Spectrum 2005; 42(10): 50-56, http://dx.doi.org/10.1109/MSPEC.2005.1515961.

101. Khanna I., Roy A., Rodgers M., Krebs H., Macko R., Forrester L. Effects of unilateral robotic limb loading on gait characteristics in subjects with chronic stroke. J Neuroeng Rehabil 2010; 7: 23, http://dx.doi.org/10.1186/1743-0003-7-23.

102. Moreno J.C., Barroso F., Farina D., Gizzi L., Santos C., Molinari M., Pons J.L. Effects of robotic guidance on the coordination of locomotion. J Neuroeng Rehabil 2013; 10: 79, http://dx.doi.org/10.1186/1743-0003-10-79.

103. Ferris D.P., Gordon K.E., Sawicki G.S., Peethambaran A. An improved powered ankle-foot orthosis using proportional myoelectric control. Gait Posture 2006; 23(4): 425-428, http://dx.doi.org/10.1016/j. gaitpost.2005.05.004.

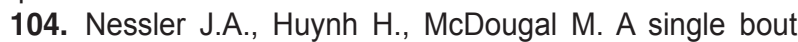
of resistance exercise does not affect nonlinear dynamics of lower extremity kinematics during treadmill walking. Gait Posture 2011; 34(2): 285-287, http://dx.doi.org/10.1016/j. gaitpost.2011.04.003.

105. de Rugy A., Loeb G.E., Carroll T.J. Muscle coordination is habitual rather than optimal. J Neurosci 2012; 32(21): 73847391, http://dx.doi.org/10.1523/JNEUROSCI.5792-11.2012.

106. Ivanenko Y.P., Cappellini G., Solopova I.A., Grishin A.A., Maclellan M.J., Poppele R.E., Lacquaniti F. Plasticity and modular control of locomotor patterns in neurological disorders with motor deficits. Front Comput Neurosci 2013; 7: 123, http://dx.doi.org/10.3389/ fncom.2013.00123.

107. Merletti R., Botter A., Cescon C., Minetto M.A., Vieira T.M. Advances in surface EMG: recent progress in clinical research applications. Crit Rev Biomed Eng 2010; 38(4): 347379, http://dx.doi.org/10.1615/critrevbiomedeng.v38.i4.20. 